\title{
New glaucoma medications: latanoprostene bunod, netarsudil, and fixed combination netarsudil-latanoprost
}

\author{
Nikki A. Mehran ${ }^{1} \cdot$ Sapna Sinha $\mathbb{D}^{1} \cdot$ Reza Razeghinejad ${ }^{1}$ \\ Received: 18 August 2019 / Revised: 8 October 2019 / Accepted: 14 October 2019 / Published online: 6 November 2019 \\ (c) The Author(s), under exclusive licence to The Royal College of Ophthalmologists 2019
}

\begin{abstract}
Reduction of intraocular pressure is the only proven method to treat glaucoma. Initial treatment of glaucoma commonly involves using anti-glaucoma medications either as monotherapy or combination therapy. Studies on aqueous humour dynamics have contributed to our understanding of aqueous outflow mechanisms that have led to the discovery of new drugs. Three new drugs (latanoprostene bunod $0.24 \%$, netarsudil $0.02 \%$, and fixed combination netarsudil $0.02 \%$-latanoprost $0.005 \%$ ) have been introduced recently in the market with novel mechanisms of action. Latanoprostene bunod $0.024 \%$ is a nitric oxide-donating prostaglandin F $2 \alpha$ analogue which increases the aqueous outflow both by uveoscleral and trabecular pathways. Netarsudil $0.02 \%$ is a potent Rho kinase/norepinephrine transporter inhibitor acting by increasing the trabecular outflow, decreasing the aqueous production, and possibly decreasing the episcleral venous pressure. This review highlights the role of these drugs in the management of glaucoma, with an overview of the major clinical trials on their efficacy, safety, and tolerability.
\end{abstract}

\section{Introduction}

Glaucoma is a chronic, progressive optic neuropathy characterized by loss of retinal ganglion cells resulting in characteristic optic nerve head cupping and visual field defects. The global burden of glaucoma is estimated to increase by over 110 million by 2040 [1]. Reduction of intraocular pressure (IOP) is the only known modifiable risk factor that can be achieved by medical, laser or surgical treatment [2-5]. IOP can be lowered medically either by decreasing aqueous production, increasing the conventional outflow or uveoscleral outflow pathway.

The first known topical anti-glaucoma medication, pilocarpine, was introduced in 1875 and 50 years later was followed by epinephrine. Timolol and latanoprost are commonly used as first-line ocular hypotensive drugs $[6,7]$. Alpha adrenergic agonists and carbonic anhydrase inhibitors are other classes of drugs that aid in lowering of IOP pharmacologically. Clinical trials showing ocular

Reza Razeghinejad

mrazeghi@willseye.org

1 Glaucoma Service, Wills Eye Hospital, Philadelphia, PA, United States hypotensive action and acceptable safety profile have contributed to the addition of latanoprostene bunod (LBN), netarsudil, and fixed combination netarsudillatanoprost (FCNL) in the market recently. LBN is a nitric oxide-donating prostaglandin which acts by increasing the aqueous outflow via both trabecular and uveoscleral pathways [8]. Netarsudil is a Rho kinase inhibitor, the only class of anti-glaucoma medications acting upon the cells of trabecular meshwork (TM) and Schlemm's canal (SC), reorganizing the extracellular matrix leading to improvement in aqueous outflow through the trabecular pathway. Its multimodal mechanism also includes a decrease in aqueous secretion and episcleral venous pressure $[5,9]$.

In some patients, effective reduction of IOP demands the addition of more than one anti-glaucoma medication leading to an increase in frequency and side effect profile with an added burden of higher cost. These factors affect compliance with questionable adherence [10]. Fixed drug combinations have the advantage of reducing the number of drops with additive mechanisms of action showing higher efficacy than individual drugs [11]. A once-daily formulation of FCNL may improve the compliance and efficacy of treatment. The three new medications, LBN, netarsudil, and FCNL are reviewed in this manuscript. 


\section{Latanoprostene bunod}

Latanoprostene bunod is a nitric oxide (NO)-donating prostaglandin analogue approved in the US for the reduction of IOP in patients with open angle glaucoma (OAG) or ocular hypertension (OHTN). LBN will be available in the European markets in near future. Latanoprost, along with other prostaglandin analogues, is most commonly used as the first-line agent in the treatment of glaucoma due to their efficacy in IOP reduction, once-daily dosing, and acceptable safety profile. NO was first discovered in the 1770s but was disregarded for medicinal purposes because it was known as an air pollutant. In the early 1900s, with the use of nitrates (e.g., nitro-glycerine) for angina, studies were conducted to characterize the physiologic responses of various tissues to these compounds [12]. Endogenous NO is generated by NO synthases and regulates blood flow by relaxing the vascular smooth muscle. In the eye, the NO relaxes the TM cells and facilitated the trabecular outflow [13, 14]. NO synthetase is mainly found in anterior segment, non-pigmented epithelium of ciliary processes, ciliary muscle, TM, SC, and collector channels [15]. These structures efficiently respond to $\mathrm{NO}$ and play a pivotal role in aqueous humour dynamics and IOP level [16]. NO markers have been found to be reduced in patients with OAG which could be one of the factors decreasing the flow through the trabecular pathway [17]. NO also regulates ocular blood flow and may promote retinal ganglion cell survival in the eye [18]. In patients with $\mathrm{OAG}$, markers for $\mathrm{NO}$ are decreased in aqueous humour, suggesting that lower NO levels may contribute to increased IOP [19].

\section{Chemistry}

LBN ophthalmic solution $0.024 \%$ is a modified prostaglandin analogue. It is a NO-donating prostaglandin F2 $\alpha$ analogue with the chemical name of 4-(nitrooxy) butyl (5Z)-7-\{(1 R,2 R,3 R,5 S)-3,5-dihydroxy-2-[(3 R)3-hydroxy-5-phenylpentyl] cyclopentyl\} hept-5-enoate and the molecular formula of $\mathrm{C}_{27} \mathrm{H}_{41} \mathrm{NO}_{8}$.

\section{Pharmacokinetics and pharmacodynamics}

LBN is hydrolysed by corneal esterases to latanoprost acid (active metabolite) and butanediol mononitrate, which is further metabolized to 1,4-butanediol (inactive metabolite) and NO (active metabolite) [20-22]. After latanoprost acid begins to circulate systemically, the liver becomes the primary source of metabolism, converting it to 1,2-dinor and 1,2,3,4-tetranor metabolites via fatty acid $\beta$-oxidation. LBN's other metabolite, butanediol mononitrate, is also metabolized which results in 1,4-butanediol and NO. Further metabolism occurs when 1,4-butanediol is oxidized to succinic acid, upon which it enters the tricarboxylic acid cycle [23]. There were no quantifiable plasma concentrations of LBN or butanediol mononitrate post-dose on day 1 or 28 in 22 healthy subjects after topical ocular administration of LBN $0.024 \%$ once daily for 28 days. Maximal plasma concentrations of latanoprost were occurring at $\sim 5$ min post-instillation in both days, and concentrations dropped below the lower limit of quantitation in the majority of subjects by $15 \mathrm{~min}$ post-instillation [24].

LBN combines the IOP-lowering effects of prostaglandin analogues by increasing the uveoscleral outflow, while NO relaxes the TM and SC and improves the trabecular outflow. Latanoprost acid binds to the prostaglandin $\mathrm{F}$ receptor in the ciliary muscle and lowers IOP through extracellular matrix remodelling, thus increasing uveoscleral outflow. NO relaxes TM and SC cells through activation of the soluble guanylyl cyclase/cyclic guanosine monophosphate signalling pathway. This results in increased levels of the cyclic guanosine monophosphate. Then cyclic nucleotide gated channels, protein kinases, and other molecules inhibiting Rho kinase are involved and lead to cytoskeletal relaxation $[19,25]$. TM cells are smooth muscle-like cells and rapidly relax and decrease their cellular volume via $\mathrm{K}$ channels in response to NO [26]. Upon ocular instillation, IOP reduction occurs $\sim 1-3 \mathrm{~h}$ after the first dosage. The maximum effects of LBN administration are reached after $11-13 \mathrm{~h}$ [27].

\section{Efficacy}

The studies conducted on the efficacy and safety of LBN are shown in Table 1. In KRONUS study conducted on normal volunteers with normal IOP, $27 \%$ reduction of IOP was observed which supports the IOP-lowering benefit of once daily LBN $0.024 \%$ in glaucoma patients even if IOP is within a normal range [28].

In the VOYAGER study four dosage strengths of LBN $(0.006,0.012,0.024$, and $0.040 \%)$ were compared with latanoprost $0.005 \%$. All were administered once daily in the evening, in patients with OAG (including pigmentary or pseudoexfoliative glaucoma) or OHTN. Significant IOP reduction of IOP was observed in all groups, but greater reductions were achieved in the LBN 0.024 and $0.040 \%$ compared with the latanoprost. The amount of IOP reduction was similar for 0.024 and $0.04 \%$ and greater than latanoprost for $1.23 \mathrm{~mm} \mathrm{Hg}$ [29].

The CONSTELLATION study was conducted on 25 patients with OAG or OHTN, the diurnal and nocturnal IOP and ocular perfusion pressure were compared between the LBN $0.024 \%$ once daily in the evening with timolol $0.5 \%$ twice daily. Both medications lowered the diurnal IOP at the same level, nocturnal IOP levels in patients receiving timolol were unchanged from baseline, but in the LBN it 


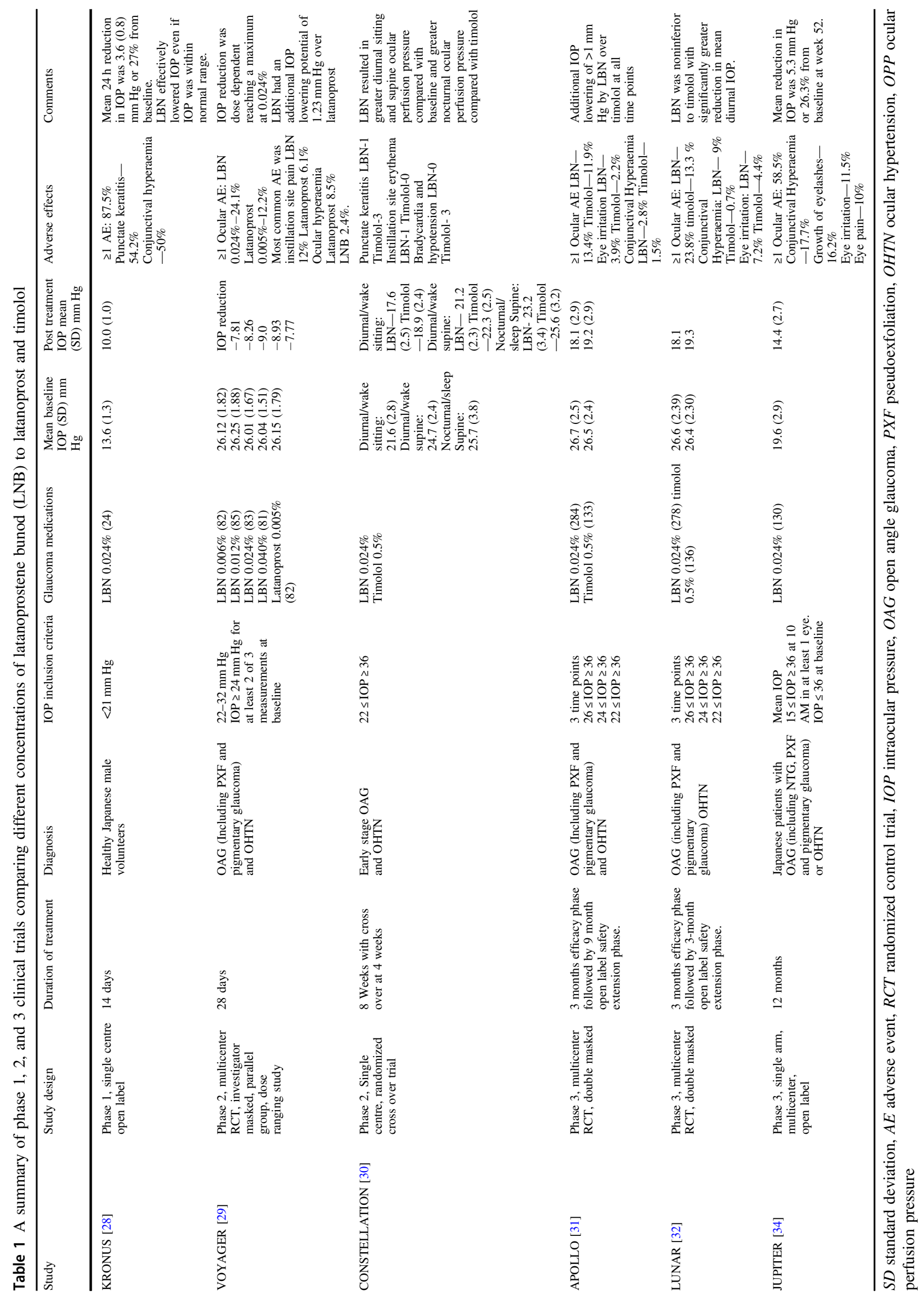


was $2.5 \mathrm{~mm} \mathrm{Hg}$ less than baseline and $2.3 \mathrm{~mm} \mathrm{Hg}$ less than timolol. LBN treatment was also associated with greater diurnal sitting and supine ocular perfusion pressure relative to baseline and greater nocturnal ocular perfusion pressure relative to timolol [30].

In the APOLLO trial, once daily LBN was compared with twice daily timolol $0.5 \%$, significantly greater mean IOP reductions to timolol at each time point throughout the 3-month double-masked treatment period was noted. Mean IOP was significantly lower in the LBN $0.024 \%$ group $(17.8-18.7 \mathrm{~mm} \mathrm{Hg})$ than in the timolol $0.5 \%$ group $(19.1-19.8 \mathrm{~mm} \mathrm{Hg})$. The percentage of patients with a mean IOP $\leq 18 \mathrm{~mm} \mathrm{Hg}$ (22.9 vs $11.3 \%)$ and IOP reduction of $\geq 25 \%$ (34.9 vs $19.5 \%$ ) was greater in the LBN than timolol [31].

Similar to APOLLO [31], the LUNAR study [32] was designed to compare the IOP-lowering effect of LBN $0.024 \%$ with timolol $0.5 \%$ in individual with $\mathrm{OAG}$ or OHTN. The patients received the medications for 3 months. IOP was checked at $8 \mathrm{AM}, 12 \mathrm{PM}$, and $4 \mathrm{PM}$ at week 2 , week 6 , and month 3 . The percentage of patients with $>25 \%$ reduction in IOP from baseline was higher in the LBN group (31.0 vs $18.5 \%$ ). Although higher percentage of subjects in the LBN group had a mean IOP $<18 \mathrm{~mm} \mathrm{Hg}$ (17.7 vs $11.1 \%)$, the difference was not statistically significant. In a pooled analysis of the APOLLO and LUNAR studies, LBN provided greater IOP reduction than timolol and maintained their effect for one year after the initiation of treatment [33].

The JUPITER study evaluated the long-term safety and the IOP-lowering efficacy of LBN over 12 months in Japanese OAG and OHTN participants. Individuals were assessed monthly after starting the LBN. A $22 \%$ reduction in IOP was achieved by the end of the first month. This percent of IOP reduction was maintained or increased through the end of the year, with study eyes achieving $26 \%$ IOP reduction [34].

\section{Side effects}

The most common ocular adverse effects of LBN through one year of treatment were conjunctival hyperaemia $(17.7 \%)$, growth of eyelashes (16.2\%), eye irritation $(11.5 \%)$, and eye pain $(10.0 \%)$, increase in iris pigmentation (9\%) [34]. Ocular adverse events were more common in the LBN (17.8\%) than timolol (11.1\%), including conjunctival hyperaemia (5.9 vs $1.1 \%$ ), eye irritation ( 4.6 vs $2.6 \%$ ), eye pain (3.6 vs $2.2 \%$ ), and ocular hyperaemia (2.0 vs $0.7 \%$ ), respectively [35]. Overall, the adverse effect profile of LBN was similar to that of prostaglandin analogues [36]. NO has a very short half-life, it is $<3 \mathrm{~s}$ in extravascular tissues. Therefore, it is highly unlikely that NO released from LBN reach the retina at toxic levels [37].

\section{Safety in pregnancy, childhood, and lactation}

Prostaglandin analogues are classified into "Category C" in pregnancy and reports indicate that $25 \%$ of the pregnant rabbits exposed to 80 times the human dose of latanoprost delivered no viable foetuses at term but no adverse effects were noted when the exposure was up to 15 times the human dosage. A small series of prospective clinical study on the latanoprost treatment in pregnant woman found no evidence of latanoprost on pregnancy or neonatal outcomes [38]. There have been conflicting views on prescribing prostaglandin analogues during pregnancy as some claim that ocular prostaglandin analogues have insufficient active ingredients to induce adverse effects on the foetus, and some believe its use is contraindicated in pregnant women [39]. There is no compelling evidence to withhold this group of medications in pregnant glaucomatous patients. However, since prostaglandins increase uterine tone and can cause reduced perfusion to the foetus, general caution is advised [40].

To assess the safety of LBN, pregnant rats were administered LBN intravenously at the dose of $150-1500 \mathrm{mcg} /$ $\mathrm{kg} /$ day. Maternal toxicity was produced at $1500 \mathrm{mcg} / \mathrm{kg} / \mathrm{day}$ ( 870 times the clinical dose). At the dose of $150 \mathrm{mcg} / \mathrm{kg} / \mathrm{day}$ (87 times the clinical dose) no adverse effect was observed in the pregnant rat and foetus. In other words, teratogenicity was observed in pregnant rats with intravenous administration at doses 87 times higher than the clinical dose. Resorption and foetal death and structural anomalies were produced at doses $\geq 300 \mathrm{mcg} / \mathrm{kg} /$ day (174 times the clinical dose). The observed malformations were anomalies of the sternum, domed head, forepaw hyperextension and hindlimb malrotation, vertebral anomalies, and delayed ossification of distal limb bones. The manufacturer does not recommend LBN use in paediatric subjects under age 16 because of potential safety concerns related to increased pigmentation following long-term chronic use. There are no data on the presence of LBN in human milk, its effects on milk production and on the breastfed infant [23].

\section{Netarsudil}

Netarsudil is a recently developed IOP-lowering medication that has been approved by the Food and Drug Administration (FDA) in the US for OAG and OHTN. Recently, the European Medicines Agency's Committee for Medicinal Products for Human Use approved the use of netarsudil $0.02 \%$ for OAG and OHTN and will be available in the markets shortly [41]. Netarsudil $0.02 \%$ is the only available glaucoma medication that exerts its IOP lowering effect via inhibiting rho-associated protein kinase while also having the benefit of a convenient, once-daily dosage schedule 
[42, 43]. The Rho kinase pathway became an area of focus in the development of anti-glaucoma medications once it was discovered that pharmacologic manipulation of the cytoskeleton of the eye's outflow pathway could lead to decreased outflow resistance [9]. Rho kinase functions include: organizing the extracellular matrix, increasing cellular stiffness, modulating cell adhesion, and promoting the contraction of actomyosin, and influencing aqueous humour outflow $[9,44,45]$. Rho kinase is a serine/threonine protein kinase that regulates cytoskeletal activities. Through its action as a downstream effector of the Rho GTPase, Rho kinase also regulates calcium-independent smooth muscle contraction [9, 44-46].

\section{Chemistry}

Netarsudil (Rho kinase inhibitor) $0.02 \%$ is supplied as a buffered aqueous solution of netarsudil dimesylate, with a $\mathrm{pH}$ of $\sim 5$ and an osmolality of $\sim 295 \mathrm{mOsmol} / \mathrm{kg}$. Each $\mathrm{mL}$ of netarsudil contains $0.2 \mathrm{mg}$ of netarsudil, and this is equivalent to $0.28 \mathrm{mg}$ of netarsudil dimesylate [47].

\section{Pharmacokinetics and pharmacodynamics}

Netarsudil is absorbed through the cornea following installation. The highest concentration of netarsudil was found in the cornea, followed by conjunctiva. Concentrations in the iris-ciliary body were notably lower [46]. Netarsudil has a notably long elimination half-life $\left(t_{1 / 2}\right)$ in the aqueous humour, conjunctiva, and vitreous humour of rabbits, lasting between 16 and $17 \mathrm{~h}$. However, its elimination half-life in the iris-ciliary body, retina-choroid plexus, and the lens was 68-112 h [48].

Netarsudil is converted to netarsudil-M1, the metabolically active form, by corneal esterase [46]. There is minimal systemic absorption of netarsudil: in studies on rabbits the highest concentrations were found to be 200- to 3000-fold lower than in the cornea and conjunctiva [46]. In a study on 18 healthy volunteers that received netarsudil $0.02 \%$ once daily for 8 days, plasma concentrations did not rise higher than the lower limit of detection $(0.11 \mathrm{ng} / \mathrm{mL})$ except in one subject [49]. Netarsudil being highly protein bound in human plasma leads to low plasma concentrations, unlikely to cause any systemic pharmacological effects after topical application. This seems to have a slow onset and prolonged duration of IOP lowering activity [49]. In animal studies, researchers could not find evidence of netarsudil metabolism when incubated within liver microsomes [50]. In studies on rabbits and monkeys, various concentrations of netarsudil produced maximum reductions in IOP between 4 and $8 \mathrm{~h}$ after their third daily dose for both species [46].

Netarsudil $0.02 \%$ is a potent rho-associated protein kinase inhibitor for both isoforms of human Rho kinases
(ROCK1 and ROCK2) and also an inhibitor of the norepinephrine transporter [46, 51]. Netarsudil is able to inhibit both ROCK1 and ROCK2 at a potency of 20 times greater than other ROCK inhibitors and its metabolite netarsudil-M1 had five times greater potency than netarsudil itself [46, 48]. Netarsudil disrupts actin stress fibres and focal adhesions in TM cells and blocks the profibrotic effects of transforming growth factor-beta 2 [46, 42, 51]. Netarsudil lowers IOP by increasing the TM outflow [44, 52], decreasing episcleral venous pressure [53], and decreasing aqueous humour production (through inhibition of the $\mathrm{Na}^{+} / \mathrm{K}^{+}$-ATPase in ciliary epithelial cells) [54]. ROCK inhibitors attenuate the effects of TGF- $\beta 2$ on human TM cells and also prevent fibrosis in the heart, lungs, liver, and kidney in animal models [44, 46]. Lin et al. found that human TM cells treated solely with TGF$\beta 2$ for one day showed an increase in fibrogenic markers upon immunostaining, but not in those that received both netarsudil and TGF- $\beta 2$. This antifibrotic activity of netarsudil may be an additional IOP lowering mechanism of netarsudil [46]. Kazemi et al. investigated the effect of netarsudil $0.02 \%$ and its vehicle on aqueous humour dynamics including episcleral venous pressure in eleven healthy human volunteers. Outflow facility was increased by $22 \%$ in the netarsudil group, but none in the vehicle group. There was no significant difference in diurnal episcleral venous pressure or uveoscleral outflow rate between the two groups [55].

\section{Efficacy}

In a multicentre study including $224 \mathrm{OAG}$ and OHTN patients netarsudil $0.02 \%$ was slightly more effective than $0.01 \%$ but less effective than latanoprost by $\sim 1 \mathrm{~mm} \mathrm{Hg}$, in patients with unmedicated IOPs of $22-35 \mathrm{~mm} \mathrm{Hg}$. The mean baseline unmedicated IOP was 25.8, 25.6, and 25.5 in the netarsudil $0.01 \%$, netarsudil $0.02 \%$, and latanoprost groups which decreased by $5.5,5.7$, and $6.8 \mathrm{~mm} \mathrm{Hg}$ on day 28 , respectively. Neither concentrations of netarsudil met the non-inferiority criteria vs latanoprost. However, in the subset of patients with baseline $\mathrm{IOP} \leq 26 \mathrm{~mm} \mathrm{Hg}$, both netarsudil and latanoprost were found to be equally efficacious [56]. Tanna et al. hypothesized that this shows netarsudil may be more efficacious in patients with lower baseline IOP, and that the mechanism behind this could be due to netarsudil's ability to decrease episcleral venous pressure [9].

Three major trials have evaluated the efficacy and safety of netarsudil; ROCKET-1 and ROCKET-2 evaluated the efficacy and safety of netarsudil $0.02 \%$ in patients with OAG and OHTN, and ROCKET-4 compared the efficacy and safety profile of netarsudil once daily vs timolol twice daily (Table 2). 


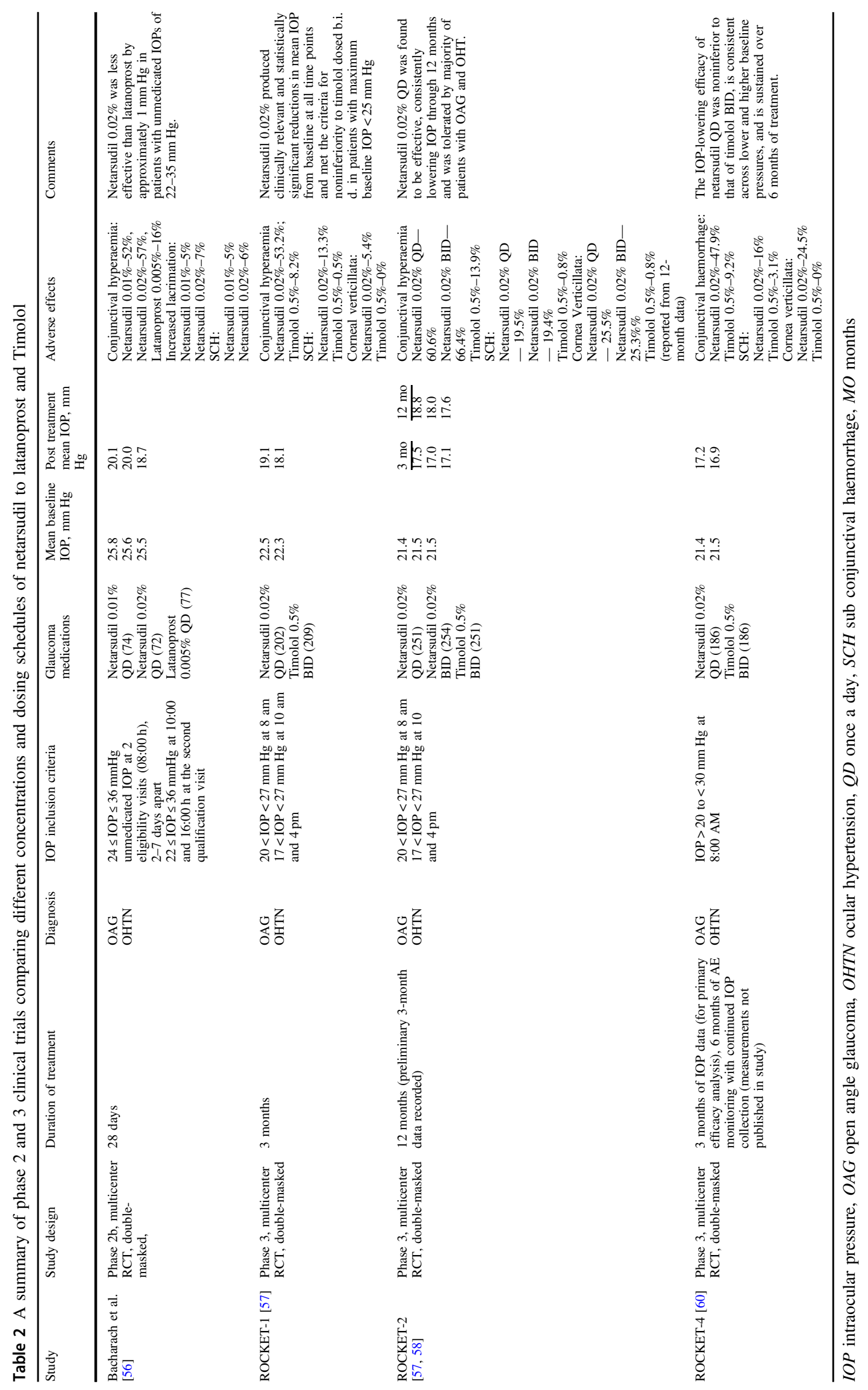


In the ROCKET-1, a 3-month long study, the posttreatment mean diurnal IOPs were $19.1 \mathrm{~mm} \mathrm{Hg}$ and 18.1 $\mathrm{mm} \mathrm{Hg}$ for the netarsudil and timolol groups, respectively. The IOP reduction with netarsudil once daily was $15-22 \%$ in comparison with $17-22 \%$ with timolol [57]. The ROCKET-2 trial was a year-long study. The patients received either netarsudil once or twice daily or timolol $0.5 \%$ twice daily. Patient IOPs were measured at 8 and 10 $\mathrm{AM}$, and $4 \mathrm{PM}$. Mean baseline IOPs were $21.4 \mathrm{~mm} \mathrm{Hg}$, $21.5 \mathrm{~mm} \mathrm{Hg}$, and $21.5 \mathrm{~mm} \mathrm{Hg}$ for the netarsudil once daily, netarsudil twice daily, and timolol groups respectively. The reductions in IOP at the end of the third month with netarsudil once daily, twice daily, and timolol were between 16 and 21\%, 22 and 24\%, and 18 and 23\%, respectively [57] and this remained at about 16.6, 20.4, and $22.1 \%$ at the end of 12-month study period.

In the ROCKET-4 trial, patients were randomized to either the netarsudil $0.02 \%$ once daily or timolol $0.5 \%$ twice daily. Percent reductions in IOP relative to the baseline ranged from 18.7 to $21.4 \%$ and 18.1 to $22.9 \%$ for netarsudil and timolol, respectively. IOPs measured at 6 months demonstrated that netarsudil maintained efficacy in lowering IOP past the 3-month efficacy end point [5].

\section{Side effects}

Conjunctival hyperaemia was the most commonly reported adverse effect [5, 56-58]. The mechanism is believed to be due to ROCK-inhibition by netarsudil which causes ROCK-mediated inhibition of calcium sensitization and leads to blood vessel smooth muscle relaxation and consequently blood vessel dilation [42, 57]. Bacharach et al. reported the conjunctival hyperaemia incidence of $52 \%$ with netarsudil 0.01 and $57 \%$ with netarsudil $0.02 \%$ (compared to $16 \%$ with latanoprost $0.005 \%$ ). Notably, the presence of conjunctival hyperaemia decreased over the course of the study to 18 and $24 \%$ in the netarsudil $0.01 \%$ and $0.02 \%$ treatment groups, respectively (compared with $11 \%$ in the latanoprost $0.005 \%$ ) [56]. However, the ROCKET-2 noted that the incidence of hyperaemia increased over the course of the study [57, 58]. Conjunctival hyperaemia incidence in the ROCKET trials occurred at incidences of $47.9-60.5 \%$ for netarsudil $0.02 \%$ and of $8.2-13.9 \%$ for timolol $0.5 \%$. The ROCKET1 study found that hyperaemia was usually reported by the investigator and was unnoticed by patients. In the ROCKET-4 trial, conjunctival hyperaemia was attributed to $4 \%$ of patients leaving the study. The authors noted that while conjunctival hyperaemia is very common in ROCK inhibitors and may be considered an intolerable adverse effect, in a meta-analysis of randomized clinical trials of prostaglandin analogues, similar rates of conjunctival hyperaemia were reported [5].
Subconjunctival haemorrhage is the second most common adverse effect of netarsudil which is commonly a small, unilateral petechial microhaemorrhages in or around the limbus [57]. The incidences of subconjunctival haemorrhage in patients using netarsudil $0.02 \%$ once daily were 13.2 , 19.5, and $16 \%$ in the ROCKET-1, ROCKET-2, and ROCKET-4 trials, respectively. Patients in the ROCKET-2 trial using $0.02 \%$ netarsudil twice daily experienced subconjunctival haemorrhage at an incidence of $19.4 \%$. Patients using timolol $0.5 \%$ twice daily experienced much lower incidences of subconjunctival haemorrhage, between $0.5 \%$ and $3.1 \%$ across the ROCKET trials $[5,57,58]$. In a trial on FCNL patients also exhibited conjunctival haemorrhage while patients using latanoprost alone did not [42, 59]. Subconjunctival haemorrhage was found to be self-limiting in most patients and typically resolved with continued use of netarsudil. In the ROCKET-2 trial, the discontinuation rate of netarsudil for subconjunctival haemorrhage was 2 and $4 \%$ for netarsudil once daily and netarsudil twice daily, respectively, whereas no patients discontinued timolol due to this adverse effect $[5,58]$.

Cornea verticillata is another prevalent adverse effect of netarsudil. It was present in incidences of 5.4, 25.5, and $24.5 \%$ in the ROCKET-1, ROCKET-2, and ROCKET-4 trials, respectively in patients using netarsudil $0.02 \%$ once daily. Patients in the ROCKET-2 trial using $0.02 \%$ netarsudil twice daily experienced corneal verticillata at an incidence of $25.3 \%$. The incidence of cornea verticillata across the ROCKET trials in those patients who received timolol was $0-3.1 \%$ [5, 57, 58]. Typically, corneal verticillata is associated with systemic agents like amiodarone or with subconjunctival administration of tobramycin or gentamicin. These agents are cationic and amphiphilic which induce phospholipidosis. This phenomenon results in the accumulation of phospholipids within the lysosomes of corneal epithelial cells [58, 60]. Corneal verticillata is usually described as mild, not associated with any visual change, and self-resolving within several months after cessation of therapy. The ROCKET-2 trial found that the mean onset time of cornea verticillata was 172.9 (range 40-396) days with once daily and 127.1 (range 14-363) days with twice daily dosing.

A subset of patients who were found to have cornea verticillata was given the option to enrol in a noninterventional Corneal Observation Study (COS). In 45 out of the 130 patients who developed cornea verticillata, 26 had resolution of corneal verticillata before the start of the study and over the course of the study, corneal verticillata fully resolved in all, but three patients. The mean time to resolution after discontinuation of the medication was 341.2 days [58].

Other side effects include instillation-site pain, erythema of the eyelid, blurred vision, increased lacrimation, and 
reduced visual acuity $[5,57,58]$. Systemic adverse effects were not observed with netarsudil in ROCKET trials; however, statistically significant reductions in mean heart rate occurred in patients receiving timolol [5, 49].

\section{Safety in pregnancy, childhood, and lactation}

Though systemic absorption of netarsudil upon ocular installation is quite low, at this time no studies have been performed on the effects of netarsudil on pregnant women $[46,47]$. Given that netarsudil is highly protein bound in human plasma; this leads to low plasma concentrations; netarsudil is considered unlikely to cause any systemic pharmacological effects following topical application [61]. Only animal studies have been done to determine the inutero effects of netarsudil. In a study using rats, embryofoetal lethality and abortions resulted from daily intravenous doses of netarsudil $\geq 0.3 \mathrm{mg} / \mathrm{kg} / \mathrm{day}$, or 126 times greater than the plasma exposure at the recommended human ophthalmic dose (RHOD). In a similar study performed with rabbits, decreased foetal weight and embryofoetal lethality resulted from daily intravenous doses of netarsudil at $5 \mathrm{mg} / \mathrm{kg} /$ day (1480 times greater than the RHOD). Absent intermediate lung lobe, gastroschisis, and umbilical herniation were the observed foetal malformations at the dose of $\geq 3 \mathrm{mg} / \mathrm{kg} /$ day (1330 times the RHOD). No foetal abnormalities were observed at plasma exposures that were at least 40 times (rat) and 214 times (rabbit) higher than the human plasma exposure with topical ocular dosing of netarsudil $0.02 \%$ [47].

In paediatric patients below the age of 18 , safety and efficacy have yet to be established [47]. Given the very low systemic absorption of netarsudil after ocular installation, it is currently believed to be unlikely to cause adverse effects on the breastfed infant. However, it is suggested to exercise caution during breastfeeding given that this topic merits further investigation [62].

\section{Fixed combination netarsudil-latanoprost}

FCNL is the first fixed combination of a prostaglandin analogue, latanoprost, and the ROCK inhibitor, netarsudil. This was recently approved by FDA for the treatment of OAG and OHTN. Netarsudil lowers IOP by increasing the trabecular outflow which complements the increased uveoscleral outflow by latanoprost.

\section{Chemistry}

Fixed combination netarsudil $0.02 \%$-latanoprost $0.005 \%$ is supplied as an isotonic, buffered aqueous solution of netarsudil mesylate and latanoprost with a $\mathrm{pH}$ of $\sim 5$. The chemical name of netarsudil dimesylate is: (S)-4-(3-amino1-(isoquinolin-6-yl-amino)-1-oxopropan2- yl) benzyl 2,4dimethylbenzoate dimesylate. Its molecular formula is $\mathrm{C}_{30} \mathrm{H}_{35} \mathrm{~N}_{3} \mathrm{O}_{9} \mathrm{~S}_{2}$. The chemical name of latanoprost is isopropyl-(Z)-7[1 R,2 R,3 R,5 S) 3,5-dihydroxy-2-[(3 R)-3hydroxy-5-phenylpentyl] cyclopentyl]-5-heptenoate. Its molecular formula is $\mathrm{C}_{26} \mathrm{H}_{40} \mathrm{O}_{5}$.

\section{Pharmacokinetics and pharmacodynamics}

The pharmacokinetics and pharmacodynamics of netarsudil is covered in the netarsudil section. Latanoprost is a lipophilic isopropyl ester prodrug, hydrolysed by corneal esterase to biologically active latanoprost acid. The peak concentration of the active drug in aqueous humour was detected $1-2 \mathrm{~h}$ after topical instillation and amounted to $15-30 \mathrm{ng} / \mathrm{ml}$. The elimination half-life was $2-3 \mathrm{~h}$ from the eye and 17 minfrom the systemic circulation. Systemic metabolism occurs in the liver via fatty acid beta oxidation, after which the majority is excreted via the urine (88\%) and the rest in the faeces [24]. The reduction of IOP begins after 3-4 h, reaches a maximum after $8-12 \mathrm{~h}$, and is maintained for at least $24 \mathrm{~h}$ [63].

Latanoprost is an ester prodrug analogue of prostaglandin F2 alpha, which reduces IOP by increasing uveoscleral outflow [64]. It exerts a modulating effect on the extracellular matrix both in the ciliary muscle $[65,66]$ and sclera [67] leading to a decrease in matrix components [68]. Alteration in the cell shape influences the extracellular matrix architecture leading to an increased uveoscleral outflow [69]. Its predominant effect on the compact anterior longitudinal muscles fibres of the ciliary body [65] leads to the reorganization of the collagen bundles and a decrease in extracellular matrix, increasing the porosity and hydraulic conductivity through the ciliary muscle [70]. Few studies have demonstrated the presence of prostaglandin receptors in TM which may contribute to improved outflow via the trabecular pathway as well [71].

\section{Efficacy}

The studies conducted on the efficacy and safety of FCNL are shown in Table 3. A 28 day double masked randomized study in 298 patients with OAG and OHTN compared the efficacy of once daily FCNL 1 (netarsudil $0.01 \%$ + latanoprost $0.005 \%$ ) and FCNL 2 (netarsudil $0.02 \%$ + latanoprost $0.005 \%$ ) with individual components of netarsudil $0.02 \%$ or latanoprost $0.005 \%$. FCNL 2 had a clinically and statistically superior ocular hypotensive efficacy relative to its individual active components [59]. On day 29, the mean diurnal IOP decreased to $17.3 \pm 2.8,16.5 \pm 2.6,18.4 \pm 2.6$, and $19.1 \pm 3.2 \mathrm{~mm} \mathrm{Hg}$ in FCNL1, FCNL 2, latanoprost and netarsudil groups, respectively. Additional IOP lowering of FCNL 2 by 1.9 vs FCNL 1 by $1.1 \mathrm{~mm} \mathrm{Hg}$ was reported 


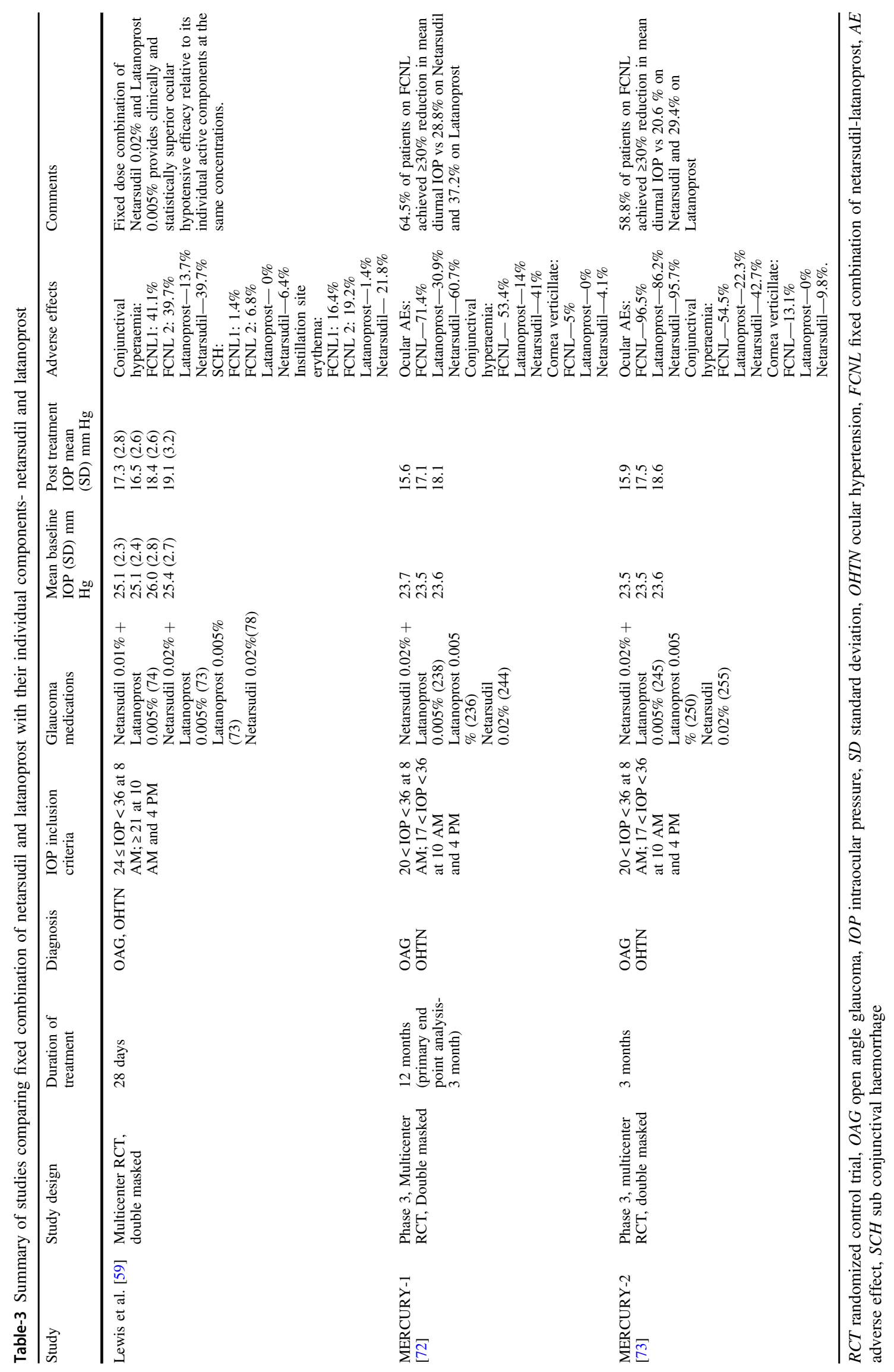


when compared with latanoprost. IOP lowering of 3.4 and $1.8 \mathrm{~mm} \mathrm{Hg}$ was noticed with FCNL 2 and FCNL 1, respectively, when compared with netarsudil $0.02 \%$. Mean IOP decreased to $16.0-18.4$ and $15.6-17 \mathrm{~mm} \mathrm{Hg}$ with FCNL 1 and FCNL 2, respectively. Interestingly, the mean IOP recorded at $36 \mathrm{~h}$ after the last dose (off-treatment) was 20.3, 19.6, 21.9, and 21.0 in FCNL1, FCNL2, latanoprost and netarsudil $0.02 \%$ groups, respectively, showing FCNL 2 to provide the maximal IOP reduction post treatment [59].

MERCURY-1 and -2 were the phase 3 trials on FCNL conducted in USA. In MERCURY-1 the patients were randomized into three groups of FCNL; netarsudil $0.02 \%$, and latanoprost $0.005 \%$. The mean baseline IOP across the three diurnal time points (8:00 AM, 10:00 AM and $4 \mathrm{PM})$ ranged from $22.4-24.8 \mathrm{~mm} \mathrm{Hg}$ for all the three treatment groups. Post treatment between week 2 and month 3, the mean IOP ranged from 14.8 to $16.2 \mathrm{~mm} \mathrm{Hg}$ for FCNL, $17.2-19 \mathrm{~mm}$ for netarsudil and $16.7-17.8 \mathrm{~mm} \mathrm{Hg}$ for latanoprost. The FCNL lowered IOP by an additional 1.8-3.0 $\mathrm{mm} \mathrm{Hg}$ compared with netarsudil and $1.3-2.5 \mathrm{~mm} \mathrm{Hg}$ compared with latanoprost, meeting the criteria for superiority to each active component. The percentage reductions from baseline in mean IOP was 30.9-36.7, 21.8-24.9, and 23.3-28.8\% for FCNL, netarsudil and latanoprost respectively. An impressive $64.5 \%$ of patients treated with FCNL achieved $\geq 30 \%$ reduction in mean diurnal IOP compared with either netarsudil (28.8\%) or latanoprost (37.2\%) [72].

In MERCURY-2, the patients were randomized into three groups of FCNL, netarsudil $0.02 \%$, and latanoprost $0.005 \%$. The mean baseline IOP across the three diurnal time points ranged from 22.4 to $24.8 \mathrm{~mm} \mathrm{Hg}$ for all the three treatment groups. Post treatment between week 2 and month 3 , the mean IOP ranged from 15.3 to $16.5 \mathrm{~mm} \mathrm{Hg}$ for FCNL, 17.4 to $19.8 \mathrm{~mm} \mathrm{Hg}$ for netarsudil, and 17.1 to 18.1 $\mathrm{mm} \mathrm{Hg}$ for latanoprost. The FCNL lowered IOP by an additional $2.2-3.3 \mathrm{~mm} \mathrm{Hg}$ compared with netarsudil and $1.5-2.4 \mathrm{~mm} \mathrm{Hg}$ compared with latanoprost, meeting the criteria for superiority to each active component. The percentage reductions from baseline in mean IOP was 30.3-34.8, 19.5-23.0, and 23.6-27.3\% for FCNL, netarsudil, and latanoprost, respectively. Mean diurnal IOP reduction of $\geq 30 \%$ was achieved in $58.8 \%$ of patients treated with FCNL, $20.6 \%$ of netarsudil, and $29.4 \%$ of latanoprost groups. These results have shown IOP reductions with once daily FCNL to be clinically superior to monotherapy with netarsudil or latanoprost [73].

MERCURY-3 is an ongoing phase 3 trial conducted at multiple sites in Europe, assessing the safety and efficacy of FCNL compared with fixed-combination bimatoprost $0.03 \%$-timolol $0.5 \%$ ophthalmic solution in subjects with OHTN and OAG. The results of this study could pave the way for the availability of FCNL at multiple sites outside the US [74].

\section{Side effects}

In MERCURY-1 trial, 73.5\% of patients on FCNL showed adverse effects at the end of the third month, as compared with $63.1 \%$ of patients on netarsudil and $40.7 \%$ of patients on latanoprost and these were similar to the results of MERCURY-2 trial. The most frequent ocular adverse event noted was conjunctival hyperaemia which was seen in $53.4 \%$ of patients in MERCURY-1 and 54.5\% in MERCURY-2, significantly higher than netarsudil $(41 \%$ in MERCURY-1 and $42.7 \%$ in MERCURY-2), and latanoprost (14\% in MERCURY-1 and 22.3\% in MERCURY-2). The hyperaemia was notably mild in $76 \%$ of patients on FCNL and was transient and self-limiting, however, it led to treatment discontinuation in $7 \%$ of patients.

Another significant ocular adverse effect noted was conjunctival haemorrhage, the incidence of which was higher in patients on netarsudil (11-13.9\%) than on FCNL $(8.6-10.5 \%)$. The incidence of cornea verticillata in patients on FCNL was $5 \%$ and $13.1 \%$ in MERCURY-1 and MERCURY-2 trials respectively. Other side effects reported were instillation site pain, eye pruritis, increased lacrimation and asymptomatic changes in corneal endothelial cells $[72,73]$.

\section{Safety in pregnancy, childhood, and lactation}

Adequate data on the use of FCNL in pregnant and lactating women are lacking as there are no well-controlled studies of FCNL or its pharmacologically active components netarsudil and latanoprost in pregnancy. There are no data on the presence of FCNL in human milk, the effects on the breastfed infant, or the effects on milk production. However, systemic exposure to netarsudil following topical ocular administration is low, and it is not known whether measurable levels of netarsudil would be present in maternal milk following topical ocular administration. While it is still essential to exercise caution in prescribing glaucoma medications to lactating women, this drug may still be prescribed based on the mother's clinical need for the drug [75].

Safety and efficacy of FCNL in paediatric population is yet to be established. Latanoprost has an acceptable safety profile with no evidence of inducing clinically meaningful or statistically significant changes in ocular development or ocular hyperpigmentation in paediatric patients with glaucoma and OHTN [76].

\section{Discussion}

LBN, netarsudil, and FCNL efficacy and safety evaluated in trials have been promising. The mechanism of action of these medications is usually a combination of mechanisms. 
Table- 4 Efficacy and mechanism of action of antiglaucoma medications $[20,21,43,72]$

\begin{tabular}{|c|c|c|c|c|c|}
\hline \multirow[t]{2}{*}{ Medication } & \multirow[t]{2}{*}{ IOP reduction } & \multicolumn{4}{|c|}{ Primary target } \\
\hline & & $\begin{array}{l}\text { Increasing } \\
\text { uveoscleral } \\
\text { outflow }\end{array}$ & $\begin{array}{l}\text { Increasing } \\
\text { trabecular } \\
\text { outflow }\end{array}$ & $\begin{array}{l}\text { Reducing } \\
\text { aqueous } \\
\text { humour } \\
\text { formation }\end{array}$ & $\begin{array}{l}\text { Reducing } \\
\text { episcleral } \\
\text { venous } \\
\text { pressure }\end{array}$ \\
\hline Prostaglandin analogues & $25 \%-33 \%$ & Yes & No & No & No \\
\hline Beta blockers & $20 \%-25 \%$ & No & No & Yes & No \\
\hline Alpha-2 agonists & $20 \%-25 \%$ & Yes & No & Yes & No \\
\hline Parasympathomimetic agents & $20 \%-25 \%$ & No & Yes & No & No \\
\hline $\begin{array}{l}\text { Topical carbonic anhydrase } \\
\text { inhibitors }\end{array}$ & $15 \%-20 \%$ & No & No & Yes & No \\
\hline Rho- kinase Inhibitors & $16-21 \%$ & No & Yes & Yes & Yes \\
\hline Latanoprostene Bunod & $32-34 \%$ & Yes & Yes & No & No \\
\hline $\begin{array}{l}\text { Fixed combination Netarsudil- } \\
\text { Latanoprost }\end{array}$ & $30.9-36.7 \%$ & Yes & Yes & Yes & Yes \\
\hline
\end{tabular}

$I O P$ intraocular pressure, $T M$ trabecular meshwork, $S C$ schlemm's canal
The primary targets of all glaucoma medications are listed in Table 4 and the only medication acting on all mechanisms of IOP reduction (increasing both uveoscleral and trabecular outflow, decreasing aqueous production and episcleral venous pressure) is FCNL.

LBN was superior to timolol and latanoprost with pressure reductions from the baseline (Table 5). LBNs adverse effects are similar to latanoprost, therefore it would be a less than ideal option in patients using a prostaglandin analogue and struggling with adverse effects. However, LBN would be a great alternative for a patient using timolol who is either unable to tolerate adverse effects or is not experiencing enough of a decrease in IOP or a patient using a prostaglandin analogue and tolerating the adverse effects but in need of a small amount of more IOP reduction [29].

Netarsudil once daily was found to be more effective than timolol. Netarsudil was less effective than latanoprost by $\sim 1 \mathrm{~mm} \mathrm{Hg}$ in patients with unmedicated IOPs in the range of $22-35 \mathrm{~mm} \mathrm{Hg}$, while showed similar efficacy when the baseline IOP was $\leq 26 \mathrm{~mm} \mathrm{Hg}$. Although a greater number of patients using netarsudil had to discontinue treatment due to the adverse effects than did patients using latanoprost or timolol, it worked well with lower baseline IOPs and may have a role in normal tension glaucoma [77]. Improved efficacy in lowering IOP in some patients may make it a worthwhile option in some glaucoma patients despite higher costs than timolol and latanoprost. FCNL was found to be clinically superior to its monotherapy of netarsudil and latanoprost [58, 71, 72].

Additional IOP lowering of 1.9 and $3.4 \mathrm{~mm} \mathrm{Hg}$ was seen with FCNL when compared with latanoprost and netarsudil, respectively. MERCURY-1 and MERCURY-2 studies have shown $58.8-64.5 \%$ of patients to have a $30 \%$ or greater reduction in IOP and $76.5-82 \%$ of patients achieving a target IOP of $18 \mathrm{~mm} \mathrm{Hg}$ or less. Patients using FCNL experienced adverse effects that appeared to be a combination of those experienced using netarsudil and latanoprost separately. While FCNL is costly, for a patient who wishes to medically lower IOP with a simple dosing schedule, it seems to be a good choice. The side effect profile of FCNL was mostly mild and limited to ocular surface $[72,73]$. The lack of systemic contraindications makes this an attractive agent for patients with beta blocker contraindications or sulfa allergies. The majority of fixed combinations glaucoma eye drops contain beta blockers, which have been reported to be less effective in patients on systemic beta blockers [78].

It is notable that many of the trials used timolol as a comparator instead of a prostaglandin analogue. In fact, timolol was used as a comparator in all three ROCKET trials for netarsudil, and was also used as a comparator in the CONSTELLATION, LUNAR, and APOLLO trials for LBN [30, 31, 43, 58, 60, 79]. Both netarsudil and LBN lack the presence of long-term trials using latanoprost as a comparator. For example, the longest trial for both netarsudil and LBN using latanoprost as a comparator was 28 days, whereas the longest trial for both netarsudil and LBN using timolol as a comparator was 12 months $[56,58,79,80]$. Latanoprost is more efficacious than timolol in lowering IOP and logically the new medications should be compared with latanoprost [81]. The is no FDA regulatory requirement to compare the new medication with timolol, but the manufacturers are interested in using timolol as a comparator against a new glaucoma medication vs latanoprost. Comparative studies of these medications with latanoprost with longer duration of follow up will help in choosing the appropriate medication in tailoring the medical treatment of patients with OAG and OHTN.

The most frequent ocular adverse effect reported uniformly by all the studies on netarsudil and FCNL was 


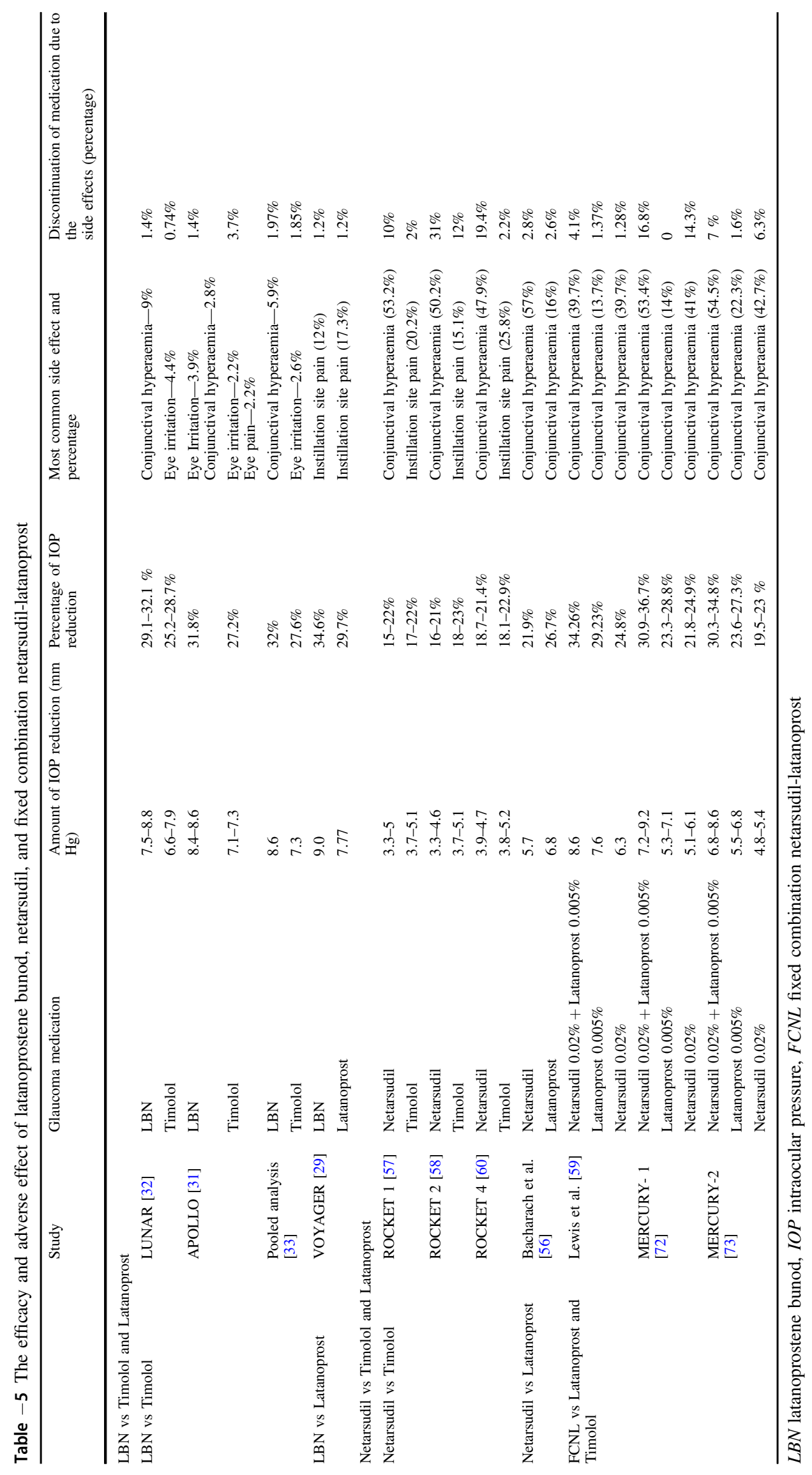


Fig. 1 Image of latanoprostene bunod, fixed combination netarsudil-latanoprost, and netarsudil ophthalmic solutions in their respective droppers. Netarsudil and fixed combination netarsudillatanoprost both have white caps and like other prostaglandin analogues, LBN is available with a turquoise cap

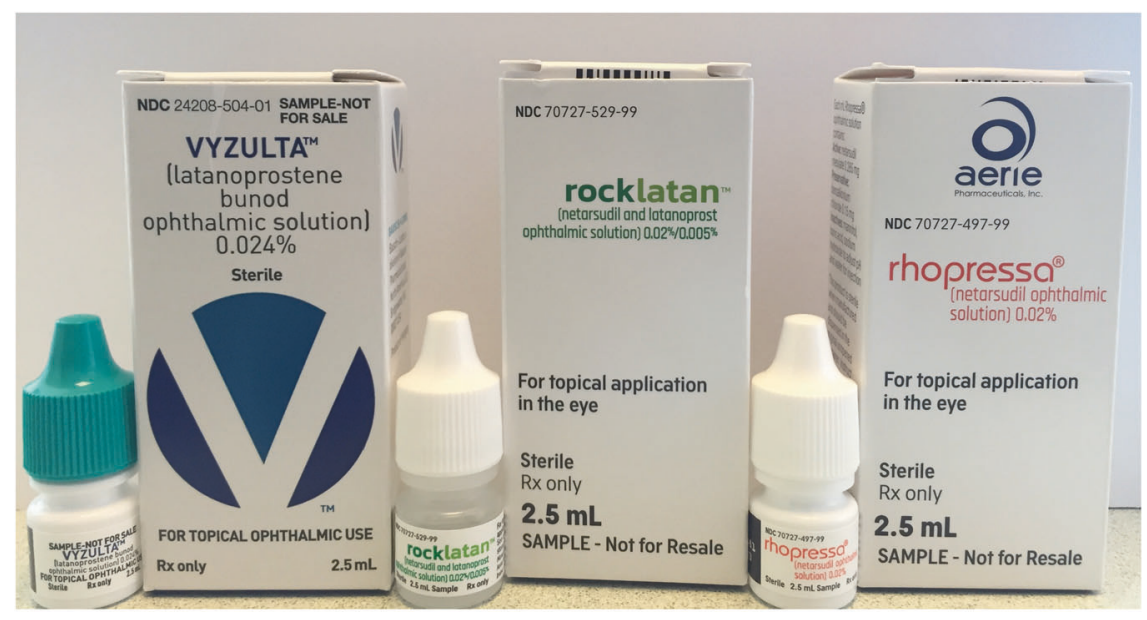

conjunctival hyperaemia, which was generally mild in severity. The incidence was $47.9-57 \%$ and $39.7-54.5 \%$ with netarsudil and FCNL, respectively [59, 72, 73]. The conjunctival hyperaemia observed is possibly due to vasodilatory effects of ROCK inhibition. The incidence of cornea verticillata in patients treated with once daily netarsudil ranged from 5.4 to $8.8 \%$ at 3 months [43], $24.5 \%$ at 6 months [60] and $25.5 \%$ at the end of month 12 [58], which is typically asymptomatic with no apparent effect on visual function and generally resolves following treatment discontinuation. The reported incidence of cornea verticillata in patients on once daily FCNL was $\leq 5 \%$ at 3 months [72], and it appears that the presence of cornea verticillata in patients using FCNL is attributed to the netarsudil component of the medication.

Almost two thirds of the patients in the studies on FCNL, LBN, and netarsudil were Caucasians, with one third contributed by African Americans and Asians were a minority. Few studies have shown a greater reduction of IOP by travoprost and latanoprost in black race [82, 83]. On account of the possibility that drugs may act differently in people of different ethnic backgrounds, a prostaglandin efficacy and safety study was undertaken by race which failed to provide evidence that race affected the IOP lowering of the medications, as the study had insufficient power to detect such a difference [84]. Further studies need to be undertaken to understand the racial differences in netarsudil and FCNL activity.

The efficacy and safety profile of netarsudil and FCNL have been studied in patients with OAG and OHTN. Patients with pseudoexfoliation glaucoma, pigmentary glaucoma, and angle closure glaucoma were excluded from these studies and their efficacy in these subgroups of patients is yet to be determined. Trials on LBN had included patients with OAG, OHTN, pseudoexfoliation, and pigmentary glaucoma. The efficacy of this drug is yet to be evaluated in angle closure glaucoma.
Benzalkonium chloride (BAK) is the commonly used preservative in anti-glaucoma medications. LBN and FCNL contains $0.02 \%$ BAK and that of netarsudil is $0.015 \%$ $[23,75,85]$. BAK has been proven to have detrimental effects to the eye including, but not limited to dry eye, TM degeneration, and corneal and conjunctival toxicity $[86,87]$. Because no preservative-free version of any of these medications exist, certain patients may not be a candidate for these medications.

Netarsudil and FCNL are available with a white cap. Typically, the white caps have been used for non-glaucoma medications and this may cause some confusion for a patient who is also using one of these other kinds of eye drops. Like other prostaglandin analogues, LBN is available with a turquoise cap (Fig. 1). The cost should also be taken into account as the patients are going to take the medications for a long time. For many glaucoma patients, medication cost can be a factor that leads to non-adherence which makes the disease progression and visual field loss more likely [88, 89]. For example timolol costs between $\$ 3.00$ and 11.00 , and latanoprost $\$ 6.00$ and 30.00 per 30 day prescription $[90,91]$. These figures for netarsudil, LBN, and FCNL are \$267-289, \$192.00-206.00, and \$267.00-289.00 per 30-day prescription for an uninsured patient [92-94]. Neither netarsudil and LBN, nor FCNL have a generic alternative available [92, 94, 95]. We do not have any information on the safety of these medications in pregnancy, lactation, and childhood. However, it should be taken into account if these medications are prescribed for a pregnant patient that the incidence of major birth defects is $2-4 \%$ and of miscarriage is $15-20 \%$ of clinically recognized pregnancies in the U.S. general population [23].

With increasing challenges with drug compliance and adherence among glaucoma patients, the need for long acting, potent new glaucoma medications cannot be over emphasized. The present scenario in many countries warrants numerous patients uncontrolled on maximal medical 
treatment to undergo laser or surgical interventions with an increased risk of vision threatening complications. With the introduction of new drugs in the market, the decision to operate may be delayed if the IOPs are well controlled on medications.

Many glaucoma patients require treatment with more than one agent to adequately control IOP and prevent glaucoma progression [20,96]. LBN and FCNL could be one of the medications that may be used if more IOP lowering effect is required in those who are already on some glaucoma medications. These two medications are taken once daily which is an important factor in patient compliance. The first-line glaucoma medication is most commonly a prostaglandin analogue. The use of this drug is discouraged in patients with active inflammation, cystoid macular oedema, and in patients presenting with allergies to its constituents. Netarsudil could be a potential option in these patients, given its comparable efficacy in lowering the IOP and simple once daily dosing schedule, if further studies show its safety in the aforementioned conditions. Given the safety, efficacy, and easy dosing of the new medications the choice of the glaucoma medications may change as we learn more about the efficacy and adverse effect of these agents.

\section{Compliance with ethical standards}

Conflict of interest The authors declare that they have no conflict of interest.

Publisher's note Springer Nature remains neutral with regard to jurisdictional claims in published maps and institutional affiliations.

\section{References}

1. Tham YC, Li X, Wong TY, Quigley HA, Aung T, Cheng CY. Global prevalence of glaucoma and projections of glaucoma burden through 2040: a systematic review and meta-analysis. Ophthalmology. 2014;121:2081-90.

2. Schulzer M. Intraocular pressure reduction in normal-tension glaucoma patients. The normal tension glaucoma study group. Ophthalmology. 1992;99:1468-70.

3. Gordon MO, Beiser JA, Brandt JD, Heuer DK, Higginbotham EJ, Johnson CA, et al. The Ocular Hypertension Treatment Study: baseline factors that predict the onset of primary open-angle glaucoma. Arch Ophthalmol. 2002;120:714-20.

4. Kass MA, Heuer DK, Higginbotham EJ, Johnson CA, Keltner JL, Miller JP, et al. The Ocular Hypertension Treatment Study: a randomized trial determines that topical ocular hypotensive medication delays or prevents the onset of primary open-angle glaucoma. Arch Ophthalmol. 2002;120:701-13. discussion 829730

5. Khouri AS, Serle JB, Bacharach J, Usner DW, Lewis RA, Braswell $\mathrm{P}$, et al. Once-daily netarsudil versus twice-daily timolol in patients with elevated intraocular pressure: the randomized phase 3 ROCKET-4 Study. Am J Ophthalmol. 2019; 204:97-104.
6. Holmstedt B, Wassen SH, Schultes RE. Jaborandi: an interdisciplinary appraisal. J Ethnopharmacol. 1979;1:3-21.

7. Li T, Lindsley K, Rouse B, Hong H, Shi Q, Friedman DS, et al. Comparative effectiveness of first-line medications for primary open-angle glaucoma: a systematic review and network metaanalysis. Ophthalmology. 2016;123:129-40.

8. Garcia GA, Ngai P, Mosaed S, Lin KY. Critical evaluation of latanoprostene bunod in the treatment of glaucoma. Clin Ophthalmol. 2016;10:2035-50.

9. Tanna AP, Johnson M. Rho kinase inhibitors as a novel treatment for glaucoma and ocular hypertension. Ophthalmology. 2018;125:1741-56.

10. Olthoff CM, Schouten JS, van de Borne BW, Webers CA. Noncompliance with ocular hypotensive treatment in patients with glaucoma or ocular hypertension an evidence-based review. Ophthalmology. 2005;112:953-61.

11. Hollo G, Topouzis F, Fechtner RD. Fixed-combination intraocular pressure-lowering therapy for glaucoma and ocular hypertension: advantages in clinical practice. Expert Opin Pharmacother. 2014;15:1737-47.

12. Michel T, Loscalzo J. Nitroglycerin and nitric oxide-a rondo of themes in cardiovascular therapeutics. New Engl $\mathrm{J}$ Med. 2015;373:1789.

13. Thoonen R, Sips PY, Bloch KD, Buys ES. Pathophysiology of hypertension in the absence of nitric oxide/cyclic GMP signaling. Curr hypertension Rep. 2013;15:47-58.

14. Buys ES, Potter LR, Pasquale LR, Ksander BR. Regulation of intraocular pressure by soluble and membrane guanylate cyclases and their role in glaucoma. Front Mol Neurosci. 2014;7:38.

15. Nathanson JA, McKee M. Alterations of ocular nitric oxide synthase in human glaucoma. Investigative Ophthalmol Vis Sci. 1995;36:1774-84.

16. Aliancy J, Stamer WD, Wirostko B. A review of nitric oxide for the treatment of glaucomatous disease. Ophthalmol Ther. 2017;6:221-32.

17. Galassi F, Renieri G, Sodi A, Ucci F, Vannozzi L, Masini E. Nitric oxide proxies and ocular perfusion pressure in primary open angle glaucoma. Br J Ophthalmol. 2004;88:757-60.

18. Pasquale LR. Vascular and autonomic dysregulation in primary open-angle glaucoma. Curr Opin Ophthalmol. 2016;27:94-101.

19. Cavet ME, Vittitow JL, Impagnatiello F, Ongini E, Bastia E. Nitric oxide (NO): an emerging target for the treatment of glaucoma. Invest Ophthalmol Vis Sci. 2014;55:5005-15.

20. Liebmann JM, Lee JK. Current therapeutic options and treatments in development for the management of primary open-angle glaucoma. Am J Manag Care. 2017;23(15 Suppl):S279-s292.

21. Hoy SM. Latanoprostene Bunod Ophthalmic Solution 0.024\%: a review in open-angle glaucoma and ocular hypertension. Drugs. 2018;78:773-80.

22. Kaufman PL, Garcia GA, Ngai P, Mosaed S, Lin KY. Latanoprostene bunod ophthalmic solution $0.024 \%$ for IOP lowering in glaucoma and ocular hypertension critical evaluation of latanoprostene bunod in the treatment of glaucoma. Expert Opin Pharmacother. 2017;18:433-44.

23. Bausch \& Lomb. Manufacturer's information: VYZULTA (latanoprostene bunod ophthalmic solution) $0.024 \%$ product monograph. Bridgewater, NJ: Bausch \& Lomb, a division of Valeant Pharmaceuticals North America LLC; 2017

24. Sjoquist B, Stjernschantz J. Ocular and systemic pharmacokinetics of latanoprost in humans. Surv Ophthalmol. 2002;47(Suppl 1): S6-12.

25. Cavet ME, DeCory HH. The role of nitric oxide in the intraocular pressure lowering efficacy of latanoprostene bunod: review of nonclinical studies. J Ocul Pharm Ther. 2018;34:52-60.

26. Dismuke WM, Mbadugha CC, Ellis DZ. NO-induced regulation of human trabecular meshwork cell volume and aqueous humor 
outflow facility involve the BKCa ion channel. Am J Physiol Cell Physiol. 2008;294:C1378-1386.

27. Bausch \& Lomb. Clinical review(s): VYZULTA (latanoprostene bunod ophthalmic solution) $0.024 \%$ product monograph. Bridgewater, NJ: Bausch \& Lomb, a division of Valeant Pharmaceuticals North America LLC; 2017.

28. Araie M, Sforzolini BS, Vittitow J, Weinreb RN. Evaluation of the effect of latanoprostene bunod ophthalmic solution, $0.024 \%$ in lowering intraocular pressure over $24 \mathrm{~h}$ in healthy japanese subjects. Adv Ther. 2015;32:1128-39.

29. Weinreb RN, Ong T, Scassellati Sforzolini B, Vittitow JL, Singh K, Kaufman PL. A randomised, controlled comparison of latanoprostene bunod and latanoprost $0.005 \%$ in the treatment of ocular hypertension and open angle glaucoma: the VOYAGER study. Br J Ophthalmol. 2015;99:738-45.

30. Liu JHK, Slight JR, Vittitow JL, Scassellati Sforzolini B, Weinreb RN, Medeiros FA, et al. Efficacy of latanoprostene bunod 0.024\% compared with timolol $0.5 \%$ in lowering intraocular pressure over $24 \mathrm{~h}$ comparison of latanoprostene bunod $0.024 \%$ and timolol maleate $0.5 \%$ in open-angle glaucoma or ocular hypertension: the LUNAR Study latanoprostene bunod $0.024 \%$ versus timolol maleate $0.5 \%$ in subjects with open-angle glaucoma or ocular hypertension: the APOLLO Study evaluation of the effect of latanoprostene bunod ophthalmic solution, $0.024 \%$ in lowering intraocular pressure over $24 \mathrm{~h}$ in healthy Japanese Subjects. Am J Ophthalmol. 2016;169:249-57.

31. Weinreb RN, Scassellati Sforzolini B, Vittitow J, Liebmann J. Latanoprostene Bunod $0.024 \%$ versus timolol maleate $0.5 \%$ in subjects with open-angle glaucoma or ocular hypertension: the APOLLO Study. Ophthalmology. 2016;123:965-73.

32. Medeiros FA, Martin KR, Peace J, Scassellati Sforzolini B, Vittitow JL, Weinreb RN. Comparison of Latanoprostene Bunod $0.024 \%$ and Timolol Maleate $0.5 \%$ in open-angle glaucoma or ocular hypertension: The LUNAR Study. Am J Ophthalmol. 2016;168:250-9.

33. Weinreb RN, Liebmann JM, Martin KR, Kaufman PL, Vittitow JL. Latanoprostene Bunod $0.024 \%$ in subjects with open-angle glaucoma or ocular hypertension: pooled phase 3 study findings. J glaucoma. 2018;27:7-15.

34. Kawase K, Vittitow JL, Weinreb RN, Araie M. Long-term safety and efficacy of latanoprostene bunod $0.024 \%$ in japanese subjects with open-angle glaucoma or ocular hypertension: The JUPITER Study. Adv Ther. 2016;33:1612-27.

35. Peace JHVJ Latanoprostene bunod ophthalmic solution $0.024 \%$ for IOP lowering in glaucoma: responder rates in phase 3 studies. Poster presented at: American Academy of Ophthalmology Meeting; October 15-8-2016, Chicago, IL. Poster PO399.

36. Kaufman PL. Latanoprostene bunod ophthalmic solution $0.024 \%$ for IOP lowering in glaucoma and ocular hypertension. Expert Opin Pharmacother. 2017;18:433-44.

37. Thomas DD, Liu X, Kantrow SP, Lancaster JR Jr. The biological lifetime of nitric oxide: implications for the perivascular dynamics of NO and $\mathrm{O}_{2}$. Proc Natl Acad Sci USA. 2001;98:355-60.

38. De Santis M, Lucchese A, Carducci B, Cavaliere AF, De Santis L, Merola A, et al. Latanoprost exposure in pregnancy. Am J Ophthalmol. 2004;138:305-6.

39. Johnson SM, Martinez M, Freedman S. Management of glaucoma in pregnancy and lactation. Surv Ophthalmol. 2001;45:449-54.

40. Razeghinejad MR. Glaucoma medications in pregnancy. Oman J Ophthalmol. 2018;11:195-9.

41. Aerie Pharmaceuticals. Aerie pharmaceuticals receives positive CHMP opinion for Rhokiinsa in the European Union. September 20th, 2019. https://eyewire.news/articles/aerie-pharmaceuticalsreceives-positive-chmp-opinion-for-rhokiinsa-in-the-europeanunion/.
42. Dasso L, Al-Khaled T, Sonty S, Aref AA. Profile of netarsudil ophthalmic solution and its potential in the treatment of openangle glaucoma: evidence to date. Clin Ophthalmol. 2018;12: 1939-44.

43. Serle JB, Katz LJ, McLaurin E, Heah T, Ramirez-Davis N, Usner $\mathrm{DW}$, et al. Two phase 3 clinical trials comparing the safety and efficacy of netarsudil to timolol in patients with elevated intraocular pressure: rho kinase elevated IOP treatment trial 1 and 2 (ROCKET-1 and ROCKET-2). Am J Ophthalmol. 2018;186: 116-27.

44. Rao PV, Pattabiraman PP, Kopczynski C. Role of the Rho GTPase/Rho kinase signaling pathway in pathogenesis and treatment of glaucoma: bench to bedside research. Exp Eye Res. 2017;158:23-32.

45. Moshirfar M, Parker L, Birdsong OC, Ronquillo YC, Hofstedt D, Shah TJ, et al. Use of Rho kinase inhibitors in ophthalmology: a review of the literature. Med Hypothesis Discov Innov Ophthalmol. 2018;7:101-11.

46. Lin CW, Sherman B, Moore LA, Laethem CL, Lu DW, Pattabiraman PP, et al. Discovery and preclinical development of netarsudil, a novel ocular hypotensive agent for the treatment of glaucoma. J Ocul Pharm Ther. 2018;34:40-51.

47. Aerie Pharmaceuticals Inc. Manufacturer's Information: Rhopressa $^{\mathrm{TM}}$ (netarsudil ophthalmic solution) $0.02 \%$ product monograph. Bedminster, NJ: Aerie Pharmaceuticals Inc Bedminster; 2017.

48. Hoy SM. Netarsudil ophthalmic solution $0.02 \%$ : first global approval. Drugs. 2018;78:389-96.

49. Levy B, Ramirez N, Novack GD, Kopczynski C. Ocular hypotensive safety and systemic absorption of AR-13324 ophthalmic solution in normal volunteers. Am J Ophthalmol. 2015;159: 980-5.e981.

50. Aerie Pharmaceuticals Inc. RHOPRESSA ${ }^{\mathrm{TM}}$ (netarsudil ophthalmic solution $0.02 \%$ ), for topical ophthalmic use: clinical pharmacology and biopharmaceutics review(s). Aerie Pharmaceuticals Inc; 2017. https://www.accessdata.fda.gov/drugsatfda_docs/nda/ 2017/208254Orig1s000ClinPharmR.pdf.

51. Sturdivant JM, Royalty SM, Lin CW, Moore LA, Yingling JD, Laethem CL, et al. Discovery of the ROCK inhibitor netarsudil for the treatment of open-angle glaucoma. Bioorg Med Chem Lett. 2016;26:2475-80.

52. Rao VP, Epstein DL. Rho GTPase/Rho kinase inhibition as a novel target for the treatment of glaucoma. BioDrugs. 2007;21: 167-77.

53. Kiel JW, Kopczynski CC. Effect of AR-13324 on episcleral venous pressure in Dutch belted rabbits. J Ocul Pharmacol Ther. 2015;31:146-51.

54. Wang RF, Williamson JE, Kopczynski C, Serle JB. Effect of 0.04\% AR-13324, a ROCK, and norepinephrine transporter inhibitor, on aqueous humor dynamics in normotensive monkey eyes. J Glaucoma. 2015;24:51-54.

55. Kazemi A, McLaren JW, Kopczynski CC, Heah TG, Novack GD, Sit AJ. The effects of netarsudil ophthalmic solution on aqueous humor dynamics in a randomized study in humans. J Ocul Pharm Ther. 2018;34:380-6.

56. Bacharach J, Dubiner HB, Levy B, Kopczynski CC, Novack GDDouble-masked. Randomized, dose-response study of AR13324 versus latanoprost in patients with elevated intraocular pressure. Ophthalmology. 2015;122:302-7.

57. Serle JB, Katz LJ, McLaurin E, Heah T, Ramirez-Davis N, Usner DW, et al. Two phase 3 clinical trials comparing the safety and efficacy of Netarsudil to Timolol in patients with elevated intraocular pressure: Rho Kinase Elevated IOP Treatment Trial 1 and 2 (ROCKET-1 and ROCKET-2). Am J Ophthalmol. 2018; $186: 116-27$ 
58. Kahook MY, Serle JB, Mah FS, Kim T, Raizman MB, Heah T, et al. Long-term Safety and ocular hypotensive efficacy evaluation of netarsudil ophthalmic solution: Rho kinase elevated IOP treatment trial (ROCKET-2). Am J Ophthalmol. 2019;200: $130-7$.

59. Lewis RA, Levy B, Ramirez N, Kopczynski CC, Usner DW, Novack GD. Fixed-dose combination of AR-13324 and latanoprost: a double-masked, 28-day, randomised, controlled study in patients with open-angle glaucoma or ocular hypertension. Br J Ophthalmol. 2016;100:339-44.

60. Khouri AS, Serle JB, Bacharach J, Usner DW, Lewis RA, Braswell $\mathrm{P}$, et al. Once-daily Netarsudil vs twice-daily Timolol in patients with elevated intraocular pressure, the randomized phase 3 ROCKET-4 Study. Am J Ophthalmol. 2019;204:97-104.

61. Aerie Pharmaceuticals Inc. Rhopressa ${ }^{\mathrm{TM}}$ (netarsudil ophthalmic solution) $0.02 \%$ Aerie Pharmaceuticals, Inc. FDA Advisory Committee Briefing Document; 2017. https://www.fda.gov/media/ 108389/download.

62. National Library of Medicine. Netarsudil. Drugs and Lactation Database (LactMed). Bethesda (MD): National Library of Medicine (US); 2006.

63. Alm A. Latanoprost in the treatment of glaucoma. Clin Ophthalmol. 2014;8:1967-85.

64. Lim KS, Nau CB, O’Byrne MM, Hodge DO, Toris CB, McLaren $\mathrm{JW}$, et al. Mechanism of action of bimatoprost, latanoprost, and travoprost in healthy subjects. A crossover study. Ophthalmology. 2008;115:790-95.e794.

65. Ocklind A. Effect of latanoprost on the extracellular matrix of the ciliary muscle. A study on cultured cells and tissue sections. Exp Eye Res. 1998;67:179-91.

66. Sagara T, Gaton DD, Lindsey JD, Gabelt BT, Kaufman PL, Weinreb RN. Topical prostaglandin F2alpha treatment reduces collagen types I, III, and IV in the monkey uveoscleral outflow pathway. Arch Ophthalmol. 1999;117:794-801.

67. Kim JW, Lindsey JD, Wang N, Weinreb RN. Increased human scleral permeability with prostaglandin exposure. Invest Ophthalmol Vis Sci. 2001;42:1514-21.

68. Weinreb RN, Kashiwagi K, Kashiwagi F, Tsukahara S, Lindsey JD. Prostaglandins increase matrix metalloproteinase release from human ciliary smooth muscle cells. Invest Ophthalmol Vis Sci. 1997;38:2772-80.

69. Stjernschantz J, Selen G, Astin M, Resul B. Microvascular effects of selective prostaglandin analogues in the eye with special reference to latanoprost and glaucoma treatment. Prog Retin Eye Res. 2000;19:459-96.

70. Toris CB, Gabelt BT, Kaufman PL. Update on the mechanism of action of topical prostaglandins for intraocular pressure reduction. Surv Ophthalmol. 2008;53:S107-20.

71. Kamphuis W, Schneemann A, van Beek LM, Smit AB, Hoyng $\mathrm{PF}$, Koya E. Prostanoid receptor gene expression profile in human trabecular meshwork: a quantitative real-time PCR approach. Invest Ophthalmol Vis Sci. 2001;42:3209-15.

72. Asrani S, Robin AL, Serle JB, Lewis RA, Usner DW, Kopczynski CC, et al. Netarsudil/Latanoprost fixed-dose combination for elevated intraocular pressure: 3-month data from a randomized phase 3 trial. Am J Ophthalmol. 2019;S0002-9394: 30284-3.

73. Walters TR, Ahmed IIK, Lewis RA, Usner DW, Lopez J, Kopczynski CC, et al. Once-daily Netarsudil/Latanoprost fixeddose combination for elevated intraocular pressure in the randomized phase 3 MERCURY-2 Study. Ophthalmol Glaucoma. 2019;2:280-9.

74. Aerie Pharmaceuticals Inc. Safety and Efficacy Study of PG324 (Netarsudil/Latanoprost $0.02 \%$ / 0.005\%) Ophthalmic Solution Compared to GANFORT ${ }^{\circledR}$ Ophthalmic Solution in Open Angle Glaucoma or Ocular Hypertension. 15 September 2017 ed.
ClinicalTrials.gov: NIH U.S. National Library of Medicine; 2019. https://clinicaltrials.gov/ct2/show/NCT03284853.

75. Aerie Pharmaceuticals Inc. Manufacturer's information: RHOPRESSA (netarsudil ophthalmic solution) $0.02 \%$ product monograph. Bedminster, NJ: Aerie Pharmaceuticals Inc.; 2017.

76. Younus M, Schachar RA, Zhang M, Sultan MB, Tressler CS, Huang $\mathrm{K}$, et al. A long-term safety study of latanoprost in pediatric patients with glaucoma and ocular hypertension: a prospective cohort study. Am J Ophthalmol. 2018;196:101-11.

77. Hedman K, Alm A. A pooled-data analysis of three randomized, double-masked, six-month clinical studies comparing the intraocular pressure reducing effect of latanoprost and timolol. Eur $\mathbf{J}$ Ophthalmol. 2000;10:95-104.

78. Schuman JS. Effects of systemic beta-blocker therapy on the efficacy and safety of topical brimonidine and timolol. Brimonidine study groups 1 and 2. Ophthalmology. 2000;107:1171-7.

79. Medeiros FA, Martin KR, Peace J, Scassellati Sforzolini B, Vittitow JL, Weinreb RN, et al. Comparison of latanoprostene bunod $0.024 \%$ and timolol maleate $0.5 \%$ in open-angle glaucoma or ocular hypertension: the LUNAR study efficacy of latanoprostene bunod $0.024 \%$ compared with timolol $0.5 \%$ in lowering intraocular pressure over $24 \mathrm{~h}$ critical evaluation of latanoprostene bunod in the treatment of glaucoma. Am J Ophthalmol. 2016;168:250-9.

80. Kaufman PL, Weinreb RN, Liebmann JM, Martin KR, Kaufman PL, Vittitow JL, et al. Latanoprostene bunod ophthalmic solution $0.024 \%$ for IOP lowering in glaucoma and ocular hypertension latanoprostene bunod $0.024 \%$ in subjects with open-angle glaucoma or ocular hypertension: pooled phase 3 study findings latanoprostene bunod $0.024 \%$ versus timolol maleate $0.5 \%$ in subjects with open-angle glaucoma or ocular hypertension: The APOLLO Study a randomised, controlled comparison of latanoprostene bunod and latanoprost $0.005 \%$ in the treatment of ocular hypertension and open angle glaucoma: the VOYAGER study. Expert Opin Pharmacother. 2017;18:433-44.

81. Camras CB, The United States Latanoprost Study Group, Comparison of latanoprost and timolol in patients with ocular hypertension and glaucoma: a six-month masked, multicenter trial in the United States. Ophthalmology. 1996;103:138-47.

82. Netland PA, Robertson SM, Sullivan EK, Silver L, Bergamini MV, Krueger S, et al. Response to travoprost in black and nonblack patients with open-angle glaucoma or ocular hypertension. Adv Ther. 2003;20:149-63.

83. Kitnarong N, Zhao Y, Netland PA, Kent AR. Efficacy of latanoprost and timolol maleate in black and white patients. Adv Ther. 2004;21:203-13.

84. Birt CM, Buys YM, Ahmed II, Trope GE. Prostaglandin efficacy and safety study undertaken by race (the PRESSURE study). J Glaucoma. 2010;19:460-7.

85. Aerie Pharmaceuticals Inc. Manufacturer's Information: ROCKLATAN (netarsudil and latanoprost ophthalmic solution) $0.02 \%$ / $0.005 \%$ product monograph. Bedminster, NJ.: Aerie Pharmaceuticals Inc.; 2019.

86. Rasmussen CA, Kaufman PL, Kiland JA. Benzalkonium chloride and glaucoma. J Ocul Pharm Ther. 2014;30:163-9.

87. Datta S, Baudouin C, Brignole-Baudouin F, Denoyer A, Cortopassi GA. The eye drop preservative benzalkonium chloride potently induces mitochondrial dysfunction and preferentially affects LHON mutant cells. Invest Ophthalmol Vis Sci. 2017;58: 2406-12.

88. Sleath B, Robin AL, Covert D, Byrd JE, Tudor G, Svarstad B. Patient-reported behavior and problems in using glaucoma medications. Ophthalmology. 2006;113:431-6.

89. Anderson DR. Collaborative normal tension glaucoma study. Curr Opin Ophthalmol. 2003;14:86-90.

90. Timolol prices, Coupons \& savings tips - GoodRx. https://www. goodrx.com/timolol. Accessed 9 Aug 2019. 
91. GoodRx. Latanoprost prices and latanoprost coupons. GoodRx. https://www.goodrx.com/latanoprost. Accessed 9 Aug 2019.

92. GoodRx. Rhopressa prices, coupons \& savings tips. GoodRx. https://www.goodrx.com/rhopressa. Accessed 9 Aug 2019.

93. OptumRx. Drug search result. OptumRx. https://www.optumrx. com/secure/member-tools/drugsearchresults. Accessed 9 Aug 2019.
94. GoodRx. Rocklatan prices, coupons \& savings tips. GoodRx. https://www.goodrx.com/rocklatan. Accessed 9 Aug 2019.

95. GoodRx. Vyzulta prices, coupons \& savings tips. GoodRx. https://www.goodrx.com/vyzulta. Accessed 9 Aug 2019.

96. Aptel F, Chiquet C, Romanet JP. Intraocular pressure-lowering combination therapies with prostaglandin analogues. Drugs. 2012;72:1355-71. 